Analitika: Jurnal Magister Psikologi UMA, Vol. 12 (1) Juni (2020)

ISSN: 2085-6601 (Print), ISSN: 2502-4590 (Online)

DOI: http://dx.doi.org/analitika.v11i1.3350

ANALITIKA

Jurnal Magister Psikologi UMA

Available online http://ojs.uma.ac.id/index.php/analitika

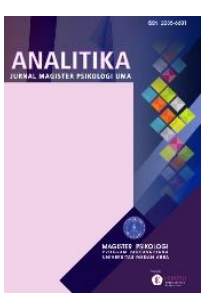

\title{
Faktor-Faktor yang Mempengaruhi Kinerja Pegawai dalam Penerapan Sidalih di Komisi Pemilihan Umum Daerah Istimewa Yogyakarta
}

\section{Factors that Affect Employee Performance in Sidalih Implementation in the Special Region of Yogyakarta Election Commission}

\author{
Paisal Akbar*, Ulung Pribadi, Eko Priyo Purnomo \\ Program Magister Ilmu Pemerintahan, Universitas Muhammadiyah Yogyakarta, Indonesia
}

Diterima: 16 Januari 2020, disetujui: 11 Juni 2020, dipublish: 30 Juni 2020

*Corresponding author: E-mail: paisal.akbar.psc19@mail.ac.id

\begin{abstract}
Abstrak
Penelitian ini bertujuan untuk mengetahui faktor apa saja yang mempengaruhi kinerja pegawai dalam penerapan Sistem Data Pemilih (Sidalih) Komisi Pemilihan Umum Daerah Istimewa Yogyakarta. Metode penelitian yang digunakan ialah metode penelitian kualitatif deskriftip, data dalam penelitian ini didapatkan dengan melakukan wawancara kepada empat orang stakeholder internal Komisi Pemilihan Umum Daerah Istimewa Yogyakarta. Selanjutnya dalam menganalisa data wawancara yang telah didapatkan data wawancara tersebut diolah melalui NVivo 12 Plus. Hasil yang ditemukan dalam peneltian ini menunjukan disiplin kerja menjadi faktor utama dalam memberikan pengaruh terhadap kinerja pegawai dengan persentase 32,10\%, faktor kedua faktor Kepemimpinan $22,40 \%$, faktor ketiga faktor Pelatihan dan Pengembangan dengan persentase 22,20\%, Sementara itu faktor Stres Kerja $\mathbf{1 4 . 0 0 \%}$ dan Kompensasi $9.30 \%$ menjadi faktor selanjutnya yang memberikan pengaruh kepada kinerja pegawai dalam penerapan Sistem Data Pemilih di Komisi Pemilihan Umum Daerah Istimewa Yogyakarta. Kinerja egawai dalam melaksanakan tugas dan fungsinya, terkhusus pegawai yang menangani Sidalih sudah dianggap sangat maksimal dengan menunjukkan totalitas kinerja yang sangat tinggi agar dapat mewujudkan data pemilih yang berkualitas.
\end{abstract}

Kata kunci: Faktor-Faktor Kinerja Pegawai; Komisi Pemilihan Umum; Sidalih

\begin{abstract}
This study aims to determine what factors affect the performance of employees in the application of the Voter Data System (Sidalih) of the Election Commission of the Special Region of Yogyakarta. The research method used is a descriptive qualitative research method, the data in this study were obtained by conducting interviews with four internal stakeholders of the Election Commission of the Special Region of Yogyakarta. Furthermore, in analyzing interview data that has been obtained interview data is processed through NVivo 12 Plus. The results found in this research show that work discipline is a major factor in influencing the performance of employees with a percentage of 32.10\%, the second factor is Leadership factor 22.40\%, the third factor is Training and Development factor with a percentage of 22.20\%, meanwhile, the factors Work Stress $14.00 \%$ and Compensation $9.30 \%$ are the next factors that influence the performance of employees in the application of the Voter Data System in the Election Commission of the Special Region of Yogyakarta. The performance of employees in carrying out their duties and functions, especially employees who handle Sidalih has been considered very maximal by showing a very high totality of performance in order to realize quality voter data.
\end{abstract}

Keywords: Employee Performance Factors; Election Commission; Sidalih

How to Cite: Akbar, P., Ulung, P. \& Eko, P.P. (2020). Faktor-Faktor yang Mempengaruhi Kinerja Pegawai dalam Penerapan Sidalih di Komisi Pemilihan Umum Daerah Istimewa Yogyakarta. Analitika: Jurnal Magister Psikologi UMA, 12 (1): 1 - 9 


\section{PENDAHULUAN}

Kinerja pegawai di maknai dengan pencapaian tugas, di mana pegawai dalam pekerjaanya dituntut untuk dapat mengikuti program kerja organisasi yang telah ditetapkan agar dapat mencapai visi, misi, dan tujuan organisasi (Sidanti, 2015). Triastuti, (2019) menilai bahwa kinerja pegawai sebagai salah satu faktor penting yang mempengaruhi kemajuan suatu organisasi, di mana semakin tinggi kualitas kinerja maka semakin cepat pencapaian tujuan efektifitas kinerja pegawai dalam sebuah organisasi. Menurut Sumolang et al., (2019) bahwa aspek kepemimpinan sangat berpengaruh dalam meningkatkan kinerja pegawai. Mulyasari, (2019) menambahkan besarnya produktivitas kinerja pegawai juga dipengaruhi oleh sikap mental dan emosional yang akan meningkat jika pegawai selalu memiliki sikap optimis dengan keyakinan bahwa hari ini harus lebih baik daripada hari kemarin.

Penggunaan teknologi informasi dapat memberikan keuntungan yang sangat besar dalam suatu lembaga, sehingga harus dimanfaatkan dengan baik serta menjadi kebutuhan yang sangat mendasar (Sari \& Warjio, 2018). Sidalih dalam perannya sebagai salah satu produk penerapan IT oleh KPU dipandang sebagai upaya double e-gove yakni tidak hanya menerapkan asas - asas $e$ government saja tetapi juga e-governance yang memberikan kesempatan masyarakat untuk berpartisipasi dan terlibat (Calista Donald J.; \& Melitski, 2007). Komara, (2018) dalam penelitiannya menjelaskan, KPU memiliki 10 sistem informasi dalam rangka untuk upaya mengefektifkan pelaksanaan tahapan, memperkuat kinerja kelembagaan dan meningkatkan peran serta masyarakat dalam pemilu. Sistem tersebut diantaranya ialah Sistem Informasi Pencalonan (Silon), Sistem Monitoring dan Informasi Keuangan (Simonika), Sistem Informasi Penyelenggara Pemilu (SIPP), Sistem Informasi Partai Politik (Sipol), Sistem Informasi Tahapan Pilkada (Sitap), Sistem Informasi Logistik (Silog), Sistem Informasi Perganitan Antar Waktu (Simpaw), Sistem Informasi Penghitungan Suara (Situng), Sistem Informasi Daerah Pemilihan (Sidapil), dan Sistem Informasi Data Pemilih (Sidalih).

Sidalih merupakan sistem informasi yang memliki peranan sangat penting dalam pelaksanaan tahapan pemilu (Komara, 2018; Mahendra, 2018; Rahmad, 2017). Hal ini disandarkan karena output dari data yang dihasilkan Sidalih menjadi landasan dasar bagi pengadaan logistik pemilihan umum, pemetaan jumlah TPS, serta sebarannya TPS tersebut di lapangan.

Komara, (2018) dalam penelitiannya mengungkapkan dengan diluncurkannya Sidalih, diharapkan dapat memberi hasil yang baik dalam jalannya proses pemilu, serta diharapkan dapat memberikan peningkatan terhadap penjaringan pemilih dilapangan. Oleh karenanya Sidalih didalam PKPU 11 Tahun 2019 tentang penyusunan daftar pemilih di dalam negeri dalam penyelenggaraan Pemilihan Umum mengamanahkan untuk melakukan penyusunan daftar pemilih baik itu Daftar Pemilih Tetap (DPT), Daftar Pemilih Tambahan (DPTb), dan Data Pemilih 
Khusus (DPK) dengan menggunakan Sistem Informasi Data Pemilih (Sidalih).

Berdasarkan penjelasan di atas, dapat diketahui bahwa kinerja pegawai dalam pelaksanaan Sidalih adalah upaya pegawai dalam mencapai tugas yang telah ditargetkan yang dalam hal ini pegawai tersebut dituntut untuk dapat mengolah dan menghasilkan data pemilih yang berkualitas, kemudian data pemilih tersebut digunakan sebagai landasan dasar pada pengadaan logistik serta tahapan-tahapan penting pemilihan umum lainnya.

Dalam berjalannya pelaksanaan suatu pekerjaan, terdapat beberapa hal yang harus diperhatikan, selain kinerja aspek teknis adapula kinerja yang merupakan bagian dari aspek non-teknis, yang menjadi faktor utama dalam kinerja adalah sumber daya manusia. Dikutip dalam beberapa penelitian terdahulu ada beberapa faktor yang mempengaruhi kinerja diantaranya ialah pertama Disiplin Kerja, disiplin kerja adalah faktor penting bagi organisasi untuk mempertahakan eksistensinya, disiplin kerja adalah sifat saling menghargai, menghormati, patuh, dan taat terhadap aturan-aturan yang telah ditetapkan secara tertulis maupun tidak tertulis, yang apabila dalam pelaksaannya terdapat pelanggaran maka yang bersangkutan tidak dapat mengelak untuk diberikan sangsi (Dotulong \& Koyongian, 2015). Kedua Pelatihan dan Pengembangan, pelatihan dan pengembangan adalah sarana bagi organisasi untuk memberikan pelajaran keterampilan kepada karyawannya dengan tujuan agar dapat meningkatkan kemampuan dalam hal manajerial dan keterampilan- keterampilan teknis lainnya (Soegoto \& Saleleng, 2015).

Ketiga Stres Kerja, stres kerja adalah perasaan tertekan yang dialami oleh pegawai dalam mengerjakan tugas pekerjaan yang diembannya, stres kerja harus menjadi perhatian khusus karena stres kerja sangat berpengaruh terhadap kinerja pegawai (Uhing \& Mandagie, 2016). Keempat Kompensasi, kompensasi adalah hak materi yang diberikan kepada pegawai sebagai honorarium atas tenaga yang telah dia berikan dalam mengerjakan pekerjaannya, jika kompensasi meningkat maka akan semakin meningkat pula kinerja pegawai tersebut (Baskoro et al., 2016). Kelima Kepemimpinan, kepemimpinan adalah kemampan seseorang dalam manajer, mengarahkan, dan memberikan pengaruh terhadap perilaku orang lain untuk mencapai tujuan tertentu dalam situasi tertentu yang dijalankan dengan rasa percaya dan penuh semangat (Syah et al., 2015) .

Berdasarkan latar belakang yang telah di uraikan di atas, maka dapat ditarik rumusan masalah yang akan diuraikan dalam penelitian ini yakni, Bagaimana kinerja pegawai dalam pelaksanaan Sidalih di KPU Daerah Istimewa Yogyakarta?, selanjutnya faktorfaktor apa saja yang mempengaruhi kinerja pegawai dalam penerapan Sidalih di KPU Daerah Istimewa Yogyakarta?, serta apakah kinerja pegawai KPU Daerah Istimewa Yogyakarta sudah seperti yang telah ditargetkan?

\section{METODE PENELITIAN}

Penelitian ini akan dilakukan di Komisi Pemilihan Umum Daerah 
Istimewa Yogyakarta (KPU-DIY), adapun alasan mengapa penelitian ini dilakukan di KPU DIY dikarenakan dalam hal pelaksanaan IT kepemiluan KPU-DIY bertanggung jawab untuk menghasilkan data pemilih yang terbaik, sehingga dapat mengakomodir hak pilih masyarakat secara maksimal serta meningkatkan partisipasi politik dan menekan angka golongan putih (golput) di wilayah Daerah Istimewa Yogyakarta. Penelitian kualitatif digunakan agar dalam pengambilan informasi dan penjabaran hasil penelitian lebih mudah, lugas, dan jelas. Penelitian kualitatif deskriptif ialah data yang berupa kata-kata hasil wawancara atau gambar-gambar yang kemudian diolah untuk memperoleh gambaran secara rinci mengenai keadaan objek atau subjek amatan (Baskoro et al., 2016; Mustofa, 2015).

Sumber data dalam penelitian ini menggunakan data primer berupa wawancara yang dilakukan kepada empat orang narasumber sebagai stakeholder internal dari KPU DIY yaitu: Ketua KPU DIY, Komisioner Bagian Data, Kepala Bagian Data, Organisasi, dan Sumber Daya Manusia, Kepala Subbagian Program dan Data, serta Operator Sistem Data Pemilih DIY. Dengan menggunakan jenis wawancara semi berstruktur yang berpedoman kepada pedoman wawancara yang telah peneliti siapkan kemudian dalam jalannya proses wawancara peneliti dapat melakukan pengembangan pertanyaan dan memfokuskan isu menarik yang dapat digali dari narasumber yang diwawancarai (Rachmawati, 2007).

Selain itu data dalam penelitian ini juga diperoleh dari sumber sekunder berupa berbagai sumber bacaan seperti buku, makalah, karya ilmiah, atau hasil penelitian yang telah dilakukan sebelumnya dan berkaitan dengan objek yang diteliti dalam penelitian ini. Kemudian penelitian ini menggunakan analisis data dengan diolah secara coding hasil wawancara melalui aplikasi pengolahan data kualitatif Nvivo 12 plus, yang mana dalam penyajiannya dapat di tampilkan berupa diagram, gambar dan tabel hasil coding wawancara tersebut.

\section{HASIL DAN PEMBAHASAN}

Analisis Faktor-Faktor Yang Mempengaruhi Kinerja Pegawai Dalam Penerapan Sidalih di KPU Daerah Istimewa Yogyakarta

a. Faktor Disiplin Kerja

Dalam hasil wawancara yang telah dilakukan, dapat diketahui bahwa tingkat disiplin kerja lebih banyak dipaparkan oleh Ketua KPU Daerah Istimewa Yogyakarta Bapak Hamdan Kurniawan hal ini dapat dilihat dari table di bawah yang menunjukkan 28,38\% hasil dari pada coding by item disiplin kerja melalui NVivo 12 Plus. Dalam pemaparan seluruh narasumber berpandangan positif terhadap disiplin kerja yang telah dilaksanakan oleh Operator Sidalih, disiplin kinerja tersebut ditunjukkan dengan kerja keras para pegawai dalam menangani sidalih ketika proses mengerjakan data dengan jadwal yang telah ditargetkan. Bahkan dalam beberapa kesempatan operator sidalih mengajukan ide kepada pimpinan untuk melakukan tindakan-tindakan teknis yang dianggap perlu guna membantu teman-teman operator di tingkat KPU Kabupaten/Kota. 


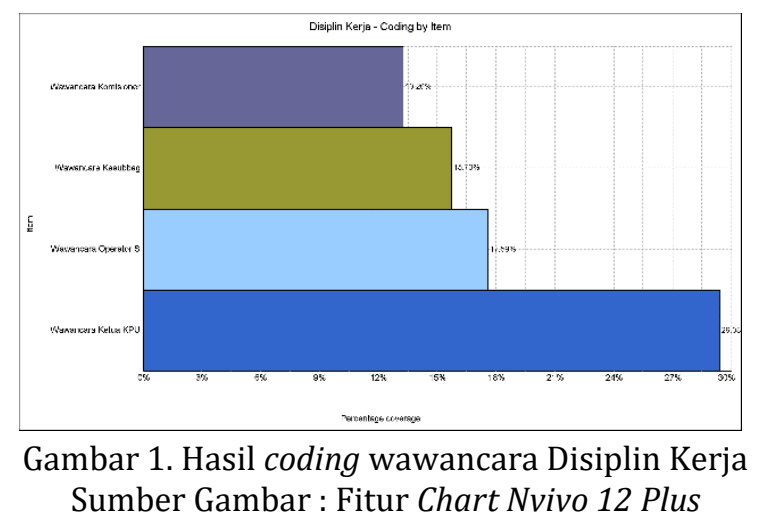

Disiplin kerja adalah faktor
penting bagi organisasi untuk mempertahakan eksistensinya demikian pula hal ini harus dimiliki oleh seorang pegawai Sidalih di KPU Daerah Istimewa Yogyakarta ketika sedang melaksanakan pengerjaan data, dalam jalannya pelaksanaan pengolahan data berdasarkan hasil wawancara dari para narasumber diketahui bahwa pegawai Sidalih KPU Daerah Istimewa Yogyakarta telah melakukan disiplin kerja dengan saling menghargai, menghormati, patuh, dan taat terhadap aturan-aturan yang telah ditetapkan (Dotulong \& Koyongian, 2015). Hal ini diterangkan secara senada oleh seluruh narasumber bahwa kedisiplinan kerja pegawai sidalih sudah tidak diragukan lagi, karena mereka dalam mengerjakan data selalu berkerja secara maksimal bahkan dengan jam kerja ekstra yang mengaharuskan mereka selalu standby alam pengerjaan data pemilih.

b. Faktor Pelatihan dan Pengembangan

Pada hasil wawancara yang telah dijalankan, dapat diketahui bahwa dalam faktor pelatihan dan pengembangan tingkat persentase tertinggi dipaparkan oleh Ketua KPU Daerah Istimewa Yogyakarta Bapak Hamdan Kurniawan hal ini dapat dilihat dari table di bawah yang menunjukkan 20,85\% hasil dari pada coding by item pelatihan dan pengembangan melalui NVivo 12 Plus. Dalam pemaparannya narasumber berpandangan bahwa pelatihan dan pengembangan merupakan komponen penting bagi Operator Sidalih agar dapat meningkatkan kinerjanya dalam melaksanakan pemutakhiran data dan daftar pemilih yang akan dijalankan, pelatihan dan pengembangan tersebut dijalankan dengan beberapa model pelatihan, yaitu pelatihan yang sifatnya secara makro (nasional) dan yang bersifat mikro (tingkat daerah).

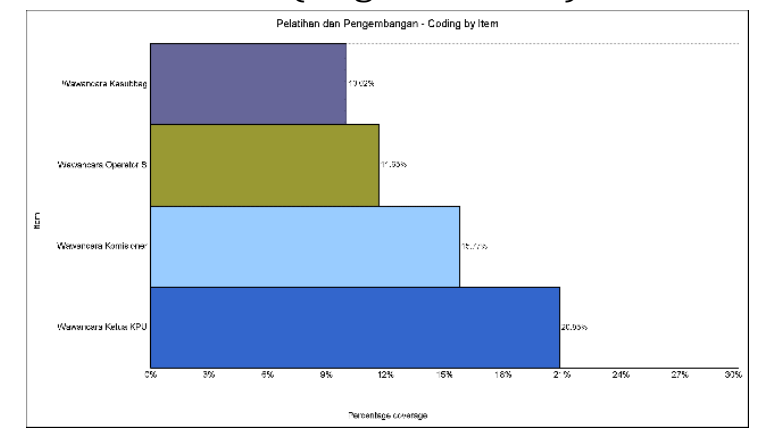

Gambar 2. Hasil coding wawancara Pelatihan dan Pengembangan

Sumber Gambar : Fitur Chart Nvivo 12 Plus

Pelatihan dan pengembangan adalah sarana bagi KPU Daerah istimewa Yogyakarta untuk memberikan pelajaran keterampilan kepada pegawainya dengan tujuan agar dapat meningkatkan kemampuan dalam hal manajerial dan keterampilan-keterampilan teknis lainnya (Soegoto \& Saleleng, 2015). Pelatihan dan pengembangan yang didapatkan oleh operator sidalih diketahui sangat berpengaruh terhadap kinerja mereka dalam mengerjakan data, pelatihan dan pengembangan itupun selalu dilakukan dengan berkelanjutan ketika terdapat perubahan regulasi 
ataupun sistem daripada aplikasi Sidalih itu sendiri.

\section{c. Faktor Stres Kerja}

Stres kerja adalah perasaan tertekan yang dialami oleh pegawai dalam mengerjakan tugas pekerjaan yang diembannya, stres kerja harus menjadi perhatian khusus karena stres kerja sangat berpengaruh terhadap kinerja pegawai (Uhing \& Mandagie, 2016). Stres kerja yang dialami oleh Operator Sidalih berpariasi mulai dari jatuh sakit karena magh, asam lambung, dan kurang istirahat karena terlalu banyak begadang. Hal ini dipaparkan oleh Kassubbag Program dan Data Bapak Meirino Setyaji S.Kom yang dalam table di bawah dapat dilihat di bawah angka stres kerja menunjukkan angka tertinggi 5,61\% dari pada coding by item stres kerja melalui NVivo 12 Plus.

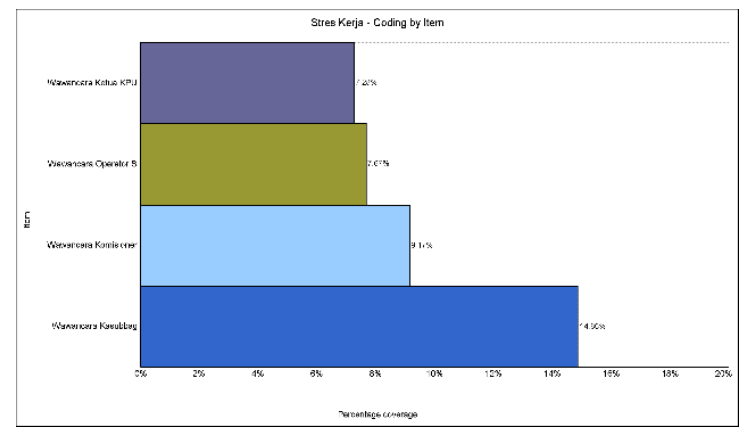

Gambar 3. Hasil coding wawancara Stres Kerja Sumber Gambar : Fitur Chart Nvivo 12 Plus

Dalam pelaksanaan pendataan pemilih Operator Sidalih tingkat Provinsi dituntut dengan beban kerja yang tidak terlalu besar jika dibandingkan dengan Operator Sidalih di tingkat Kabupaten/Kota. Tugas daripada operator Sidalih tingkat Provinsi ialah menjalankan koordinasi, dan monitoring terhadap jalannya proses pendataan pemilih yang dilakukan oleh KPU Kabupaten/Kota. Namun meskipun demikian bukan berarti Operator Sidalih di Provinsi tidak bekerja, malah mereka menunjukkan kerja sama tim yang baik dengan selalu mendampingi KPU Kabupaten/Kota dalam tahapan-tahapan kritis pengerjaan data yang sangat menguras tenaga. Hal ini diwujudkan dengan beragam kegiatan yang dilakukan Operator Sidalih tingkat Provinsi mulai dari melakukan koordinasi melalui grupgrup Whatsapp kepada kendala-kendala apa saja yang dihadapi operator sidalih Kabupaten/Kota, hingga melakukan supervise monitoring secara langsung ke KPU Kabupaten/Kota.

\section{d. Faktor Kompensasi}

Faktor Kompensasi tidak terlalu berpengaruh terhadap kinerja dari pada Operator Sidalih tingkat Provinsi, pemberian kompensasi kepada Operator Sidalih tingkat Provinsi sudah sesuai dengan regulasi angaran yang telah ditetapkan. Hal ini dipaparkan oleh Kassubbag Program dan Data Bapak Meirino Setyaji S.Kom yang dalam table di bawah dapat dilihat persentase hasil wawancara terkait kompensasi menunjukkan angka tertinggi 5,61\% dari pada coding by item kompensasi melalui NVivo 12 Plus.

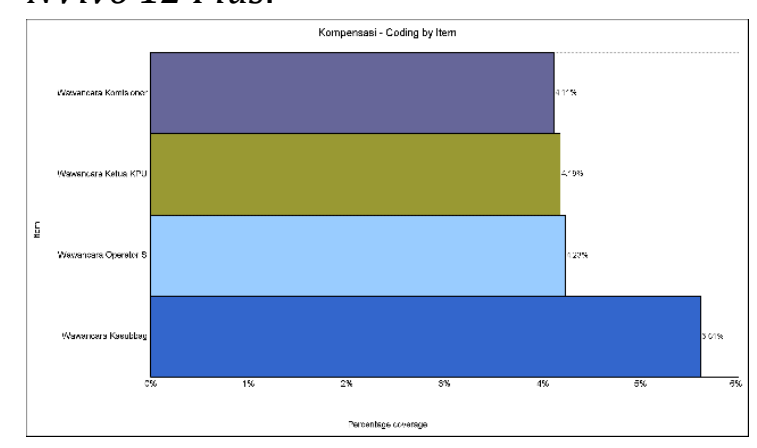

Gambar 4. Hasil coding wawancara Kompensasi Sumber Gambar : Fitur Chart Nvivo 12 Plus

Kompensasi adalah hak materi yang diberikan kepada pegawai sebagai 
honorarium atas tenaga yang telah dia berikan dalam mengerjakan pekerjaannya, jika kompensasi meningkat maka akan semakin meningkat pula kinerja pegawai tersebut (Baskoro et al., 2016). Tinggi kompensasi yang diberikan seharusnya berjalan lurus dengan tingkat tenaga yang harus dikeluarkan, semakin besar tenaga yang dikeluarkan harusnya kompensasi yang diterima semakin besar pula, namun pada kenyataannya kompensasi Operator Sidalih tidak berbanding lurus dengan tenaga ekstra yang mereka berikan. Standarisasi honor yang diberikan oleh KPU Berlaku merata untuk seluruh Indonesia sehingga ditemukan banyak sekali keluhan dari Operator Sidalih tingkat Kabupaten/Kota terhadap kompensasi yang mereka terima yang dianggap kurang sesuai dengan beban kerja yang mereka terima.

e. Faktor Kepemimpinan

Faktor Kepemimpinan

berpengaruh terhadap kinerja Operator Sidalih KPU DIY, karena dari karakter kepemimpinan yang dibangun menentukan iklim kerja yang akan dirasakan oleh Operator Sidalih sehingga sedikit banyaknya akan berpengaruh kepada ouput kinerja yang akan dihasilkan. Berdasarkan pemaparan Komisioner Divisi Program dan Data Bapak Wawan Budiyanto dalam hal kepemimpinan persentase hasil wawancara terkait kepemimpinan menunjukkan angka tertinggi 17,97\% dari pada hasil coding by item kepemimpinan melalui NVivo 12 Plus yang dapat dilihat dalam table di bawah. Dalam penjelasannya Bapak Wawan Budiyanto menginginkan terbangunnya kepemimpinan yang terbuka dan memiliki komunikasi yang sehat antara pimpinan dan Operator Sidalih DIY.

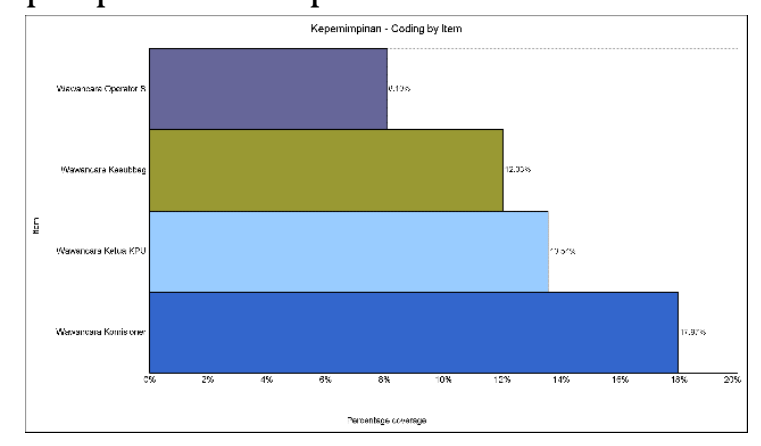

Gambar 5. Hasil coding wawancara Kepemimpinan

Sumber Gambar : Fitur Chart Nvivo 12 Plus

Kepemimpinan ialah kemampuan seseorang dalam manajer, mengarahkan, dan memberikan pengaruh terhadap perilaku orang lain untuk mencapai tujuan tertentu dalam situasi tertentu yang dijalankan dengan rasa percaya dan penuh semangat (Sumolang et al., 2019; Syah et al., 2015). Iklim kepemimpinan yang dibangun didalam KPU DIY sudah menggambarkan kepemimpinan yang mampu untuk menghasilkan manajerial yang baik dan memberikan pencapaian hasil yang maksimal, dengan pola komunikasi yang sehat dan terbuka antar pimimpinan dan operator sidalih menjadikan KPU DIY salah satu KPU yang memiliki prestasi ketepatan dan keupdatean data pemilih yang unggul di antara provinsi lainnya di Indonesia.

Secara keseluruhan berdasarkan hasil coding wawancara dari narasumber dengan menggunakan aplikasi pengolahan data kualitatif NVivo 12 Plus melalui fitur Crosstab Query, menunjukkan bahwa faktor efektifitas kinerja Operator Sidalih dalam penerapan Sidalih di KPU Daerah Istimewa Yogyakarta ialah dipengaruhi 
oleh faktor disiplin kerja sebagai faktor yang tertinggi dengan persentase mencapai 32,10\%, kemudian selanjutnya di ikuti oleh faktor kepemimpinan dengan persentase sebesar 22,40\%, faktor pelatihan dan pengembangan dengan persentase $22,20 \%$, faktor stres kerja dengan persentase 14,00\%, dan faktor kompensasi dengan persentase 9,30\%. Meskipun persentase stres kerja dan kompensasi relatif kecil dalam memberikan pengaruh terhadap kinerja Operator Sidalih namun dua faktor ini harus menjadi perhatian yang tak kalah penting dari 3 faktor lainnya.

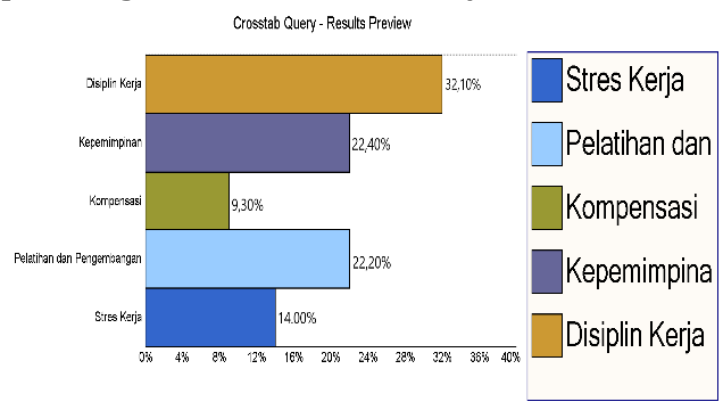

Gambar 6. Persentase Tingkat Faktor yang Mempengaruhi Kinerja Pegawai Sumber Gambar : Fitur Crosstab Query Nvivo 12 Plus

Disiplin Kerja adalah faktor yang sangat tinggi dalam mempengaruhi kinerja Operator Sidalih, sifat-sifat saling menghargai, menghormati, patuh, dan taat terhadap aturan-aturan yang telah ditetapkan secara tertulis maupun tidak tertulis telah dijalankan oleh Operator Sidalih dalam melaksanakan tugas mereka (Dotulong \& Koyongian, 2015). Secara keseluruhan berdasarkan hasil wawancara dari narasumber mereka mengapresiasi dan memberikan opini positif terhadap pelaksanaan disiplin kerja yang telah dilakukan oleh Operator Sidalih dalam menjalankan tugas dan fungsinya sehingga terwujud iklim kerja yang nyaman dan dapat mendukung terwujudnya hasil pengerjaan data yang maksimal.

\section{SIMPULAN}

Terdapat lima faktor yang mempengaruhi kinerja pegawai dalam penerapan Sidalih di KPU Daerah Istimewa Yogyakarta. Pertama, faktor disiplin kerja, kedua, faktor pelatihan dan kepemimpinan, ketiga, faktor stres kerja, keempat, faktor kompensasi, dan yang kelima, faktor kepemimpinan.

Berdasarkan hasil olah data wawancara menggunakan aplikasi analisis data kualitatif NVivo 12 Plus dengan menggunakan fitur Croostab Query, ditemukan bahwa disiplin kerja menjadi faktor yang utama dalam mempengaruhi kinerja pegawai ketika menerapkan Sidalih di KPU Daerah Istimewa Yogyakarta dengan persentase $32,10 \%$, kemudian dilanjutkan dengan faktor kepemimpinan $22,40 \%$, faktor pelatihan dan pengembangan dengan persentase yang sama $22,20 \%$, faktor stres kerja $14.00 \%$, dan pada urutan terakhir faktor kompensasi sebesar 9,30\%. Faktor disiplin kerja menjadi faktor yang tertinggi dan dominan mempengaruhi kinerja pegawai dalam penerapan Sidalih, hal ini karena disiplin kerja yang dilakukan oleh para Operator Sidalih sudah dirasa sangatlah maksimal dengan totalitas kinerja yang tinggi, hal ini digambarkan dengan keaktifan para operator dalam mengolah data, serta upaya-upaya inovatif yang mereka berikan kepada lembaga agar hasil data pemilih yang kemudian dilahirkan menjadi data pemilih yang terbaik. 


\section{DAFTAR PUSTAKA}

Baskoro, D., Hutomo, D., \& Hariani, D. (2016). Bidang Pendidik Dan Tenaga Kependidikan Dinas Pendidikan Kota Semarang. Journal of Public Policy and Management Review, 5(4), 245-259.

Sidanti, \& Heny. (2015). Pengaruh Lingkungan Kerja, Disiplin Kerja dan Motivasi Kerja Terhadap Kinerja Pegawai Negeri Sipil di Sekretariat DPRD Kabupaten Madiun. Jurnal JIBEKA, 9(1), 44-53.

Calista Donald J.;, \& Melitski, J. (2007). EGovernment and E-Governance: Converging Constructs Of Public Sector Information and Communication Technologies. Public Administration Quarterly, $\quad 31 \quad(1 / 2)(1), \quad 1-34$. https://doi.org/10.1007/s13398-014-0173-7.2

Dotulong, L., \& Koyongian, A. (2015). Analisis Disiplin Kerja, Tingkat Pendidikan, Pengembangan Karir Terhadap Kinerja Pegawai Pada Dinas Sosial Provinsi Sulawesi Utara. Jurnal Riset Ekonomi, Manajemen, Bisnis Dan Akuntansi, 3(2), 4454.

Mustofa, A. (2015). Implementasi Kebijakan Pendaftaran Pemilihan Umum Kepala Daerah Kota Batu Tahun 2012. Jurnal Ilmu Sosial dan Ilmu Politik Universitas Tribhuwana Tunggadewi, 4(2), 42443.

Komara, J. M. (2018). Faktor-Faktor yang Mempengaruhi Behavioral Intention Terhadap Pemanfaatan Sistem Informasi Data Pemilih (Sidalih) Pada Pilkada Serentak Tahun 2015 di Kabupaten Bantul. http://repository.umy.ac.id/handle/123456 $789 / 25375$

Mahendra, I. (2018). Implementasi Kebijakan Pendataan Pemilih Dalam Pemilihan Umum Kepala Daerah Kota Malang 2013 (Policy Implementation of Voters Data Collection In Mayor Election Of Malang City 2013). Jurnal Ilmiah Ilmu Sosial Dan Ilmu Politik, 8(1), 28-36.

Mulyasari, I. (2019). Pengaruh Kecerdasan Emosional Dan Kompetensi Terhadap Kinerja Pegawai. Journal of Management Review, 2(2), 190. https://doi.org/10.25157/jmr.v2i2.1786

Rachmawati, I. N. (2007). Pengumpulan Data Dalam Penelitian Kualitatif: Wawancara. Jurnal Keperawatan Indonesia, 11(1), 35-40. https://doi.org/10.7454/jki.v11i1.184

Rahmad, P. N. (2017). Pemutakhiran Data Pemilih Pada Pemilihan Bupati dan Wakil Bupati Kabupaten Bengkalis Di Kecamatan
Mandau dan Kecamatan Bantan Tahun 2015. Jurnal Online Mahasiswa Fakultas Ilmu Sosial Dan Ilmu Politik Universitas Riau, 13(3), 1576-1580.

Sari, I. R., \& Warjio, W. (2018). Perilaku Pemilih Etnik Batak terhadap Pemilihan Kepala Daerah. Politeia: Jurnal Ilmu Politik, 10(2), 6o-68.

https://doi.org/10.32734/politeia.vioi2.628

Sidanti, \& Heny. (2015). Pengaruh Lingkungan Kerja, Disiplin Kerja dan Motivasi Kerja Terhadap Kinerja Pegawai Negeri Sipil di Sekretariat DPRD Kabupaten Madiun. Jurnal JIBEKA, 9(1), 44-53.

Soegoto, A. S., \& Saleleng, M. (2015). Pengaruh Lingkungan Kerja, Motivasi, Pelatihan Dan Kompensasi, Terhadap Kinerja Pegawai Pada Dinas Pertanian Kabupaten Sorong Selatan. Jurnal Riset Ekonomi, Manajemen, Bisnis Dan Akuntansi, 3(3), 695-708.

Sumolang, D. T., Tucunan, A. A. T., \& Maramis, F. R. R. (2019). Hubungan antara pemberian insentif dan kepemimpinan dengan kinerja pegawai di rumah sakit bhayangkara tingkat III manado. Jurnal KESMAS, 8(6), 178-185.

Syah, D., Cangara, H., \& Sultan, I. (2015). Opini dan sikap masyarakat terhadap pembaharuan dan kepemimpinan bupati nurdin abdullah dalam memajukan bantaeng sebagai kota industri dan wisata. Jurnal Komunikasi KAREBA, 4(3), 300-3014.

Triastuti, D. A. (2019). Pengaruh Lingkungan Kerja, Kompetensi Dan Iklim Organisasi Terhadap Kinerja Pegawai. Journal of Management Review, 2(2), 203. https://doi.org/10.25157/jmr.v2i2.1796

Uhing, Y., \& Mandagie, A. S. (2016). Pengaruh Lingkungan Kerja, Komunikasi Dan Stres Kerja Terhadap Kinerja Pegawai Pada Politeknik Kesehatan Manado. Jurnal Riset Ekonomi, Manajemen, Bisnis Dan Akuntansi, 4(1), 344-354. 